\title{
COMBINATION OF COGNITIVE AND QUANTITATIVE ASPECTS TO ESTIMATE THE DEGREE OF EMOTIONS
}

\author{
MANH HUNG NGUYEN \\ Posts and Telecommunications Institute of Technology (PTIT), Hanoi, Vietnam \\ UMI UMMISCO 209 (IRD/UPMC), Hanoi, Vietnam \\ nmh.nguyenmanhhung@gmail.com,mhnguyen@ptit.edu.vn
}

\begin{abstract}
Emotions play a more and more important role in many fields of computer sciences such as ambient intelligence, interaction human - machine, affective computing, etc. This paper firstly constructs a logical framework to represent the qualitative cognitive factor of emotion based on a logic of belief and a logic of time. Secondly, it constructs a hedge algebra and its extension with fuzzy logic to represent the quantitative factor of emotions. These two aspects of emotion are then combined to estimate the degree of emotions based on the degree of their cognitive factors.
\end{abstract}

Keywords. Logical framework, hedge algebra, fuzzy logic, emotions.

\section{INTRODUCTION}

Emotions play a more and more important role in many fields of computer sciences. The researches aim at developing interaction systems that are closer and more attractive to their users, in particular by endowing machines with the ability to predict, understand, and process emotions such as that in the fields of ambient intelligence, interaction human - machine, affective computing, etc. There are some motivations for reason why emotions become an active research area in computer science. First, having emotional abilities enable agents more believable. Second, emotions have an impact on cognition. Many psychologists proposed models of the impact of emotions on cognitions. Third, that is because of the birth of affective computing (Picard [28]) whose objective is to construct a transparent and adaptive interface between human and machine. This gives computers the human-like abilities of observation, interpretation and generation of affect features, including user's emotions. The ability of interpretation seem to be at the core of emotional processing because it requires technologies which enable computers to understand, represent and reason about emotions. Consequently, there are many researches on emotions in computer sciences. These attempts could be regrouped into three mains directions. First, there are many works on representing the concept of emotions as the work of Van Dyke Parunak et al. [27], and Stephane [35]. Second, the works which try to formalize some emotions such as the model of Meyer [20], Ochs et al. [24, 25], Adam et al. [1], and Bonnefon et al. [3, 4, 21]. Third, the works which try to calculate the degree of emotions such as that of Steunebrink et al. $[37,36]$. The work in this paper lies on the boundary of the second and the third direction: formalize the concept and estimate the degree of emotion.

In order to construct an emotional model, computer scientists capitalize on psychological theories of emotion. There are many theories of emotions in psychology (de Sousa [34]), such as feelings theories which argue that emotions are feelings caused by changes in physiological conditions relating to the autonomic and motor functions (James-Lange [18], Cannon-Bard [5], Schacter-Singer [32]); 
appraisal theories which consider emotion as a subjective evaluation of the environment in relation to the agent's goals (Arnold [2], Frijda [11], Lazarus [19], Roseman and Smith [31]), and cognitive theories which say that emotions are characterized by their associated cognitions and therefore, can be described as a set of beliefs, desires and feelings (Ortony et al. [26], Oakley [23], Reisenzein [30]), etc. Most emotional applications for computers are built on the appraisal and cognitive theories of emotions, which assume that emotions are closely tied to changes in beliefs and desires such as the cognitive structure of emotion of Ortony et al. [26], the cognitive pattern of emotion of Lazarus [19] and the belief-desire theory of emotion (BDTE) of Reisenzein [30]. The appraisal and cognitive theories of emotions seem to be suitable to models constructed for interaction systems because: (i) their position on the awareness of emotions enables agents to recognize their emotion as well as that of their partners, and (ii) these theories assume that each emotion is characterized by its proper cognitive structure, this feature enables the modeler to construct emotions by considering primitive cognitive operators, such as belief and desire.

On the line with previous works [22], the combination of a formal logic for qualitative aspect and a fuzzy logic for quantitative aspect is used in this paper. But this is not applied for trust/distrust, this is applied for emotions. The model of emotion in this paper is also based on the cognitive structure as proposed by Ortony et al. [26], Frijda [11] as well as those of Reisenzei [30] and Scherer et al. [33]. From these theories of emotions, The proposed model is constructed on two levels. At the qualitative cognitive level, some emotions (cognitive aspect) is formalized in a formal logic based on the logic of beliefs and choices as the one of Herzig and Longin [14] (a refinement from Cohen and Levesque [9]), the logic of time (introduced by Arthur Prior [29]), and dynamic logic introduced by Fischer and Ladner [10] and Harel et al. [13]. This part of work is closed to the work of Adam et al. [1], and Bonnefon et al. [3, 4, 21]. At the quantitative level, the quantitative aspect of emotions is estimated by using a hedge algebra to represent many different (and fuzzy) degree of emotions as well as that of their cognitive factors. This hedge algebra is based on the hedge algebra of Nguyen and Wechler $[6,17]$, and its extension with fuzzy logic (Nguyen et al. $[15,16]$ ).

The model is then used to combine the qualitative and the quantitative aspects of some emotions. Particularly, the degree of joy, distress, hope, fear, satisfaction, disappointment, fear-confirmed, relief are estimated. There are some reasons that why only these eight emotions are selected to model. First, they are well known and documented in the field of psychology. Most of them are cognitively defined in the work of Ortony et al. [26], Frijda [11] as well as those of Reisenzei [30] and Scherer et al. [33]. Second, there are many works in the field of computer science which also modeled these emotions, such as the works of Adam et al. [1], Bonnefon et al. [3, 4, 21], and Steunebrink et al. $[37,36]$. Third, these eight emotions have the same (and simple) cognitive structure. They concern only the individual felling about an event which just happens. So the same logic could be used to model all of them. While other emotions (such as anger, gratitude...) have a more complex cognitive structure. They concern not only the new event, but also the felling about an action of other individual. So some other logic is needed to cover these complex emotions. This could be perspective work in the near future.

This paper is organized as follows: Secsion 2. introduces the logical framework to represent emotions based on their cognitive factors. Session 3. introduces the hedge algebra to represent many degree of emotions and that of their cognitive factors. Session 4. combines the cognitive and qualitative aspects of emotions. Session 5. compares and discusses about some closely related works. Session 6. discusses about some limits of the model. The final session is a conclusion and future works. 


\section{LOGICAL FRAMEWORK}

This section introduces a logical framework to cognitively represent emotions. This logic is mainly based on the logic of Bonnefon et al. [3, 4, 21], the logic of beliefs and choices as the one of Herzig and Longin [14] (a refinement from Cohen and Levesque [9]), the logic of time (introduced by Arthur Prior [29]), and dynamic logic introduced by Fischer and Ladner [10] and Harel et al. [13].

\subsection{Syntax}

The syntactic primitives of the logic are as follows: a nonempty finite set of agents $A G T=$ $\left\{i_{1}, i_{2}, \ldots, i_{n}\right\}$, a nonempty finite set of atomic events $E V T=\left\{e_{1}, e_{2}, \ldots, e_{p}\right\}$, and a nonempty set of atomic propositions $A T M=\left\{p_{1}, p_{2}, \ldots\right\}$. The language of the logic is defined by the following BNF :

$$
\varphi:=p|\neg \varphi| \varphi \vee \varphi|\mathrm{X} \varphi| \mathrm{X}^{-1} \varphi|\mathrm{G} \varphi| \operatorname{Bel}_{i} \varphi \mid \operatorname{Choice}_{i} \varphi
$$

where $p$ ranges over $A T M$, The classical boolean connectives $\wedge$ (conjunction), $\rightarrow$ (material implication), $\leftrightarrow$ (material equivalence), $\top$ (tautology) and $\perp$ (contradiction) are defined from $\neg$ (negation) and $\vee$ (disjunction). $\mathrm{X} \varphi$ reads " $\varphi$ will be true next instant". $\mathrm{X}^{-1} \varphi$ reads " $\varphi$ was true at the previous instant". G $\varphi$ reads " henceforth, $\varphi$ is true ". $\operatorname{Bel}_{i} \varphi$ reads " agent $i$ believes that $\varphi$ is true ". Choice $i \varphi$ reads " agent $i$ prefers that $\varphi$ be true".

The following abbreviations are defined:

$$
\begin{gathered}
\mathrm{F} \varphi \stackrel{\text { def }}{=} \neg \mathrm{G} \neg \varphi, \\
\operatorname{Goal}_{i} \varphi \stackrel{\text { def }}{=} \mathrm{Choice}_{i} \mathrm{FBel}_{i} \varphi, \\
\operatorname{Poss}_{i} \varphi \stackrel{\text { def }}{=} \neg \mathrm{Bel}_{i} \neg \varphi .
\end{gathered}
$$

$\mathrm{F} \varphi$ reads " $\varphi$ will be true in some future instants". $\operatorname{Goal}_{i} \varphi$ reads " agent $i$ has the goal (chosen preference) that $\varphi$ be true ". $\operatorname{Poss}_{i} \varphi$ reads "agent $i$ believes that it is possible $\varphi$ ".

\subsection{Semantics and axiomatics}

The logic for each operator is used as follows:

- A semantic based on linear time described by a sequence (or story) of time points is used for temporal operators. (This semantics is very close to CTL* [8])

$$
\begin{aligned}
\mathrm{X} \varphi & \leftrightarrow \neg \mathrm{X} \neg \varphi, \\
\varphi & \leftrightarrow \mathrm{XX}^{-1} \varphi, \\
\varphi & \leftrightarrow \mathrm{X}^{-1} \mathrm{X} \varphi, \\
\mathrm{G} \varphi & \leftrightarrow \varphi \wedge \mathrm{XG} \varphi, \\
\mathrm{G}(\varphi \rightarrow \mathrm{X} \varphi) & \rightarrow(\varphi \rightarrow \mathrm{G} \varphi) .
\end{aligned}
$$

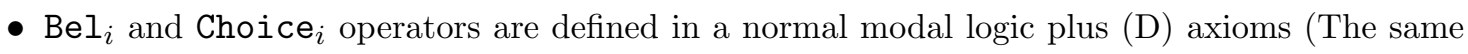


notation of modal logic axioms introduced by Chellas in [7].

$$
\begin{aligned}
\mathrm{Bel}_{i} \varphi & \leftrightarrow \mathrm{Bel}_{i} \operatorname{Bel}_{i} \varphi, \\
\neg \mathrm{Bel}_{i} \varphi & \leftrightarrow \mathrm{Bel}_{i} \neg \mathrm{Bel}_{i} \varphi, \\
\mathrm{Choice}_{i} \varphi & \leftrightarrow \mathrm{Bel}_{i} \operatorname{Choice}_{i} \varphi, \\
\neg \mathrm{Choice}_{i} \varphi & \leftrightarrow \mathrm{Bel}_{i} \neg \operatorname{Choice}_{i} \varphi .
\end{aligned}
$$

\section{HEDGE ALGEBRA}

This section introduces a hedge algebra to represent the degree of emotions. This hedge algebra is based on the hedge algebra theory of Nguyen and Wechler $[6,17]$ and its extension with fuzzy logic $[16,15]$.

The hedge algebra is a set $A X=\{X, G, H, \leqslant\}$, where:

- $X$ : the basic set of $A X X=\{0$ (not at all), very low, low, little low, average, little high, high, very high, 1 (absolute)\}.

- $G$ : the set of generators $G=\{$ low, average, high $\}$.

- $H$ : the set of linguistic hedges (also called unary operators, or hedge operations) $h=$ $\{$ very, little\}.

- $\leqslant$ : is an ordered relation between any two elements of $X: 0 \leqslant$ very low $\leqslant$ low $\leqslant$ little low $\leqslant$ average $\leqslant$ little high $\leqslant$ high $\leqslant$ very high $\leqslant 1$.

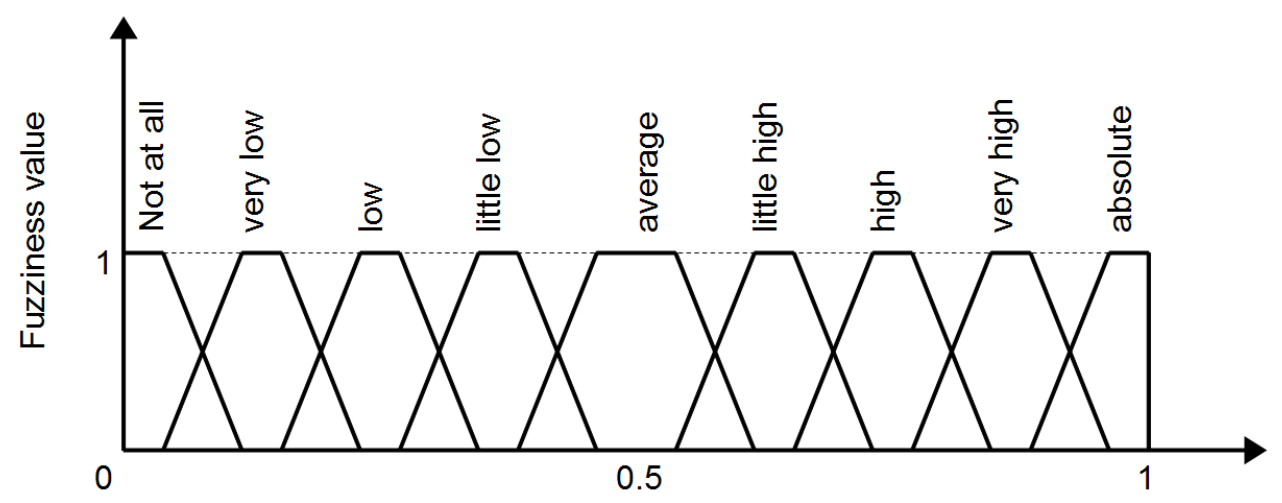

Figure 1. The fuzziness of linguistic hedges associated with emotions and their cognitive factors

This algebra provide a set of hedges which could be associated with any concept of emotion. For instance, with joy, there could have many variations of joy: not joy at all, very low joy, low joy, little low joy, average joy, little high joy, high joy, very high joy, and absolute joy. These variations have different degree. The degree of each depends on the fuzziness measure [16] of the linguistic associated with it. This algebra intuitively defines the fuzziness of each element as indicated in Figure 1. 
In this model, the degree of a variation of an emotion (or its cognitive factors) is considered as the fuzziness measure of the linguistic hedge associated with it

$$
d(\langle h e d g e\rangle\langle\text { object }\rangle)=f m(\langle h e d g e\rangle)
$$

where $\langle$ hedge $\rangle \in A X$ is any linguistic hedge in the hedge algebra. $\langle$ object $\rangle$ could be an emotion or a cognitive factor of emotion. $f m(x)$ is the fuzziness measure of the linguistic hedge $x$.

For instance, the degree of very low joy is the same as the fuzziness measure of the hedge very low $(d($ very low joy $)=f m$ (very low $))$, or the degree of very high joy is the same as the fuzziness measure of the hedge very high ( $d$ (very high joy) $=f m$ (very high) $)$.

\section{COMBINATION OF COGNITIVE AND QUANTITATIVE ASPECTS OF EMOTIONS}

This section presents the formalization of emotions, based on their cognitive structure as proposed by Ortony et al. [26], Frijda [11] as well as those of Reisenzei [30] and Scherer et al. [33]. And then, the degree of these emotions is estimated based on the combination of formal logic and fuzzy logic.

\subsection{Joy/Distress}

Joy is defined by two main factors [26]: (i) a proposition $\varphi$ is desirable for agent $i$, and (ii) agent $i$ just experienced that $\varphi$ is the case. The concept of Joy is accordingly represented as:

$$
\operatorname{Joy}_{i} \varphi=\mathrm{X}^{-1} \operatorname{Goal}_{i} \varphi \wedge \mathrm{Bel}_{i} \varphi \text {. }
$$

While the second factor, $\mathrm{Bel}_{i} \varphi$, has only two possible values of true or false (or yes/no, 1/0), the first factor, $\operatorname{Goal}_{i} \varphi$, has many possible values corresponding to different degree of agent $i$ 's desire for $\varphi$ : the more agent $i$ desires for $\varphi$, the more agent $i$ is happy when he is aware that $\varphi$ is realized, and vice versa. So the degree of $\operatorname{Joy}_{i} \varphi$ is estimated as:

$$
d\left(\operatorname{Joy}_{i} \varphi\right)=f_{\text {spa }}\left(d\left(\operatorname{Goal}_{i} \varphi\right), d\left(\operatorname{Bel}_{i} \varphi\right)\right)
$$

where $f_{\text {spa }}$ is a single-proportional-aggregation (SPA) mapping: $f_{\text {spa }}:[0,1]^{2} \rightarrow[0,1]$ which satisfies the following conditions:

(1) $f_{\text {spa }}(x, 0)=0$,

(2) $0 \leq f_{\text {spa }}(x, 1) \leq 1$,

(3) $\quad f_{\text {spa }}\left(x_{1}, 1\right) \leq f_{\text {spa }}\left(x_{2}, 1\right)$ if $x_{1} \leq x_{2}$.

For instance, when using $f_{\text {spa }}(x, y)=x * y$, the degree of joy depends on that of goal and believe is indicated in Table 1.

The same analysis applies to Distress, it is defined by two main factors [26]: (i) A proposition $\varphi$ is undesirable for agent $i$, and (ii) agent $i$ just experienced that $\varphi$ is the case. The concept of Distress is accordingly represented as:

$$
\operatorname{Distress}_{i} \varphi=\mathrm{X}^{-1} \operatorname{Goal}_{i} \neg \varphi \wedge \operatorname{Bel}_{i} \varphi \text {. }
$$


And the degree of $\operatorname{Distress}_{i} \varphi$ is estimated as:

$$
\begin{aligned}
d\left(\operatorname{Distress}_{i} \varphi\right) & =f_{\text {spa }}\left(d\left(\operatorname{Goal}_{i} \neg \varphi\right), d\left(\operatorname{Bel}_{i} \varphi\right)\right) \\
& =f_{\text {spa }}\left(1-d\left(\operatorname{Goal}_{i} \varphi\right), d\left(\operatorname{Bel}_{i} \varphi\right)\right)
\end{aligned}
$$

where $f_{s p a}$ is a $S P A$ mapping ${ }^{1}$. Table 1 shows the variation of degree of $\operatorname{Distress}_{i} \varphi$ regarding the degree of $\operatorname{Goal}_{i} \neg \varphi$ and $\operatorname{Bel}_{i} \varphi$.

Table 1. Variations of joy and distress' degree based on their contribution factors

\begin{tabular}{|c|c|c|c|c|}
\hline Goal $_{i} \varphi$ & Goal $_{i} \neg \varphi$ & $\operatorname{Bel}_{i} \varphi$ & $\operatorname{Joy}_{i} \varphi$ & Distress $_{i} \varphi$ \\
\hline not at all & absolute & yes & not at all & absolute \\
very low & very high & yes & very low & very high \\
low & high & yes & low & high \\
little low & little high & yes & little low & little high \\
average & average & yes & average & average \\
little high & little low & yes & little high & little low \\
high & low & yes & high & low \\
very high & very low & yes & very high & very low \\
absolute & not at all & yes & absolute & not at all \\
\hline
\end{tabular}

\subsection{Hope/Fear}

Hope is defined by two factors [26]: (i) A proposition $\varphi$ is desirable for agent $i$, and (ii) agent $i$ believes that $\varphi$ may be true in the future. The concept of Hope is accordingly represented as:

$$
\operatorname{Hope}_{i} \varphi=\operatorname{Goal}_{i} \varphi \wedge \operatorname{Poss}_{i} \mathrm{~F} \varphi \text {. }
$$

In this cognitive structure, both factors $\operatorname{Goal}_{i} \varphi$ and $\operatorname{Poss}_{i} \mathrm{~F} \varphi$ could have many possible values corresponding to different degree of agent $i$ 's desire for $\varphi$, and the possibility of $\varphi$ may be true in some future instants. The more agent $i$ desires for $\varphi$, the more agent $i$ hopes that $\varphi$ is realized, and vice versa. The bigger the possibility of $\varphi$ could be true in some future instant, the more agent $i$ hopes that $\varphi$ is realized, and vice versa. So the degree of $\operatorname{Hope}_{i} \varphi$ is estimated as:

$$
d\left(\operatorname{Hope}_{i} \varphi\right)=f_{d p a}\left(d\left(\operatorname{Goal}_{i} \varphi\right), d\left(\operatorname{Poss}_{i} \mathrm{~F} \varphi\right)\right)
$$

where $f_{d p a}$ is a double-proportional-aggregation (DPA) mapping: $f_{d p a}:[0,1]^{2} \rightarrow[0,1]$ which satisfies the following conditions:

$$
\begin{array}{ll}
(1) & \min (x, y) \leq f_{d p a}(x, y) \leq \max (x, y), \\
(2) & f_{d p a}\left(x_{1}, y\right) \leq f_{d p a}\left(x_{2}, y\right) \text { if } x_{1} \leq x_{2}, \\
(3) & f_{d p a}\left(x, y_{1}\right) \leq f_{d p a}\left(x, y_{2}\right) \text { if } y_{1} \leq y_{2} .
\end{array}
$$

\footnotetext{
${ }^{1}$ It is easy to prove that the degree of $\mathrm{Goal}_{i} \varphi$ is inversely proportional to the degree of Goal ${ }_{i} \neg \varphi$, so in this model, the degree of $\mathrm{Goal}_{i} \varphi$ is used as the complement of the degree of $\mathrm{Goal}_{i} \neg \varphi$ in the interval $[0,1]$ : $d\left(\operatorname{Goal}_{i} \varphi\right)=1-d\left(\operatorname{Goal}_{i} \neg \varphi\right)$
} 
For instance, when using $f_{d p a}(x, y)=\frac{x+y}{2}$, the degree of hope depends on that of goal and possible is indicated in Table 2.

The same analysis applies to Fear, it is defined by two factors [26]: (i) A proposition $\varphi$ is undesirable for agent $i$, and (ii) agent $i$ believes that $\varphi$ may be true in the future. The concept of Fear is accordingly represented as:

$$
\operatorname{Fear}_{i} \varphi \stackrel{\text { def }}{=} \operatorname{Goal}_{i} \neg \varphi \wedge \operatorname{Poss}_{i} \mathrm{~F} \varphi
$$

And the degree of $\operatorname{Fear}_{i} \varphi$ is estimated as:

$$
d\left(\operatorname{Fear}_{i} \varphi\right)=f_{d p a}\left(d\left(\operatorname{Goal}_{i} \neg \varphi\right), d\left(\operatorname{Poss}_{i} \mathrm{~F} \varphi\right)\right)
$$

where $f_{d p a}$ is a $D P A$. For instance, when using $f_{d p a}(x, y)=\frac{x+y}{2}$, the degree of fear depends on that of its cognitive factors is indicated in Table 3 .

\begin{tabular}{|c|c|c|c|c|c|c|c|c|c|c|}
\hline & \multicolumn{9}{|c|}{$\operatorname{Poss}_{i} \mathrm{~F} \varphi$} \\
\hline & & 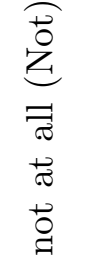 & 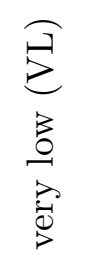 & $\begin{array}{l}\underset{\Theta}{\Theta} \\
\stackrel{0}{0}\end{array}$ & 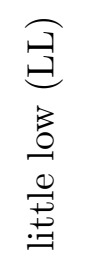 & 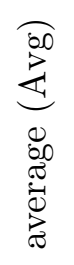 & 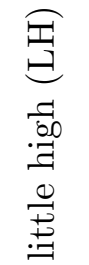 & 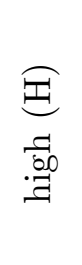 & 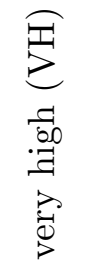 & 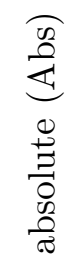 \\
\hline \multirow{9}{*}{ 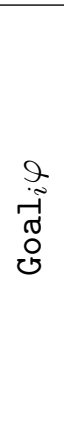 } & not at all & Not & VL & VL & $\mathrm{L}$ & $\mathrm{L}$ & LL & LL & Avg & Avg \\
\hline & very low & VL & VL & $\mathrm{L}$ & $\mathrm{L}$ & LL & LL & Avg & Avg & Avg \\
\hline & low & VL & $\mathrm{L}$ & $\mathrm{L}$ & LL & LL & Avg & Avg & Avg & LH \\
\hline & little low & $\mathrm{L}$ & $\mathrm{L}$ & LL & LL & Avg & Avg & Avg & $\mathrm{LH}$ & LH \\
\hline & average & $\mathrm{L}$ & LL & $\mathrm{LL}$ & Avg & Avg & Avg & $\mathrm{LH}$ & LH & $\mathrm{H}$ \\
\hline & little high & LL & LL & Avg & Avg & Avg & $\mathrm{LH}$ & LH & $\mathrm{H}$ & $\mathrm{H}$ \\
\hline & high & LL & Avg & Avg & Avg & LH & LH & $\mathrm{H}$ & $\mathrm{H}$ & VH \\
\hline & very high & Avg & Avg & Avg & $\mathrm{LH}$ & LH & $\mathrm{H}$ & $\mathrm{H}$ & VH & VH \\
\hline & absolute & Avg & Avg & $\mathrm{LH}$ & LH & $\mathrm{H}$ & $\mathrm{H}$ & VH & VH & Abs \\
\hline
\end{tabular}

Table 2. Variations of hope's degree based on its contribution factors

The relationship between the degree of hope and that of fear about the same event is represented in the Fig. 2. These results confirm one more time the fact that hope and fear are not always a bipolar pair of emotion. So it could neither simply estimate their degree as: $d\left(\operatorname{Hope}_{i} \varphi\right)=1-d\left(\operatorname{Fear}_{i} \neg \varphi\right)$, nor: $d\left(\operatorname{Fear}_{i} \varphi\right)=1-d\left(\operatorname{Hope}_{i} \neg \varphi\right)$.

\subsection{Satisfaction/Disappointment}

Satisfaction is defined by three factors [26]: (i) Agent $i$ desired a proposition $\varphi$; (ii) agent $i$ used to believe that $\varphi$ might be true in the near future; and (iii) agent $i$ now experiences that $\varphi$ is really the case. The concept of Satisfaction is accordingly represented as:

$$
\operatorname{Satisfaction}_{i} \varphi=\mathrm{X}^{-1}\left(\operatorname{Goal}_{i} \varphi \wedge \operatorname{Poss}_{i} \mathrm{~F} \varphi\right) \wedge \operatorname{Bel}_{i} \varphi .
$$


Table 3. Variations of fear's degree based on its contribution factors

\begin{tabular}{|c|c|c|c|c|c|c|c|c|c|c|}
\hline & \multicolumn{9}{|c|}{$\operatorname{Poss}_{i} F \varphi$} \\
\hline & & 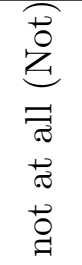 & $\begin{array}{l}\text { B } \\
\sum \\
0 \\
0 \\
0 \\
0 \\
0 \\
0\end{array}$ & $\begin{array}{l}\underset{\theta}{\Theta} \\
\stackrel{3}{0}\end{array}$ & 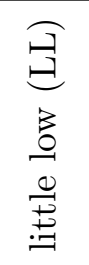 & 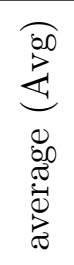 & 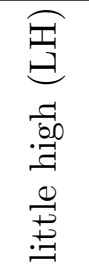 & 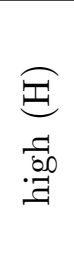 & 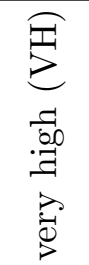 & 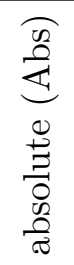 \\
\hline \multirow{9}{*}{ 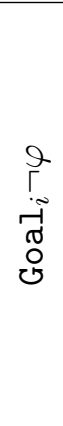 } & not at all & Not & VL & VL & $\mathrm{L}$ & $\mathrm{L}$ & LL & LL & Avg & Avg \\
\hline & very low & VL & VL & $\mathrm{L}$ & $\mathrm{L}$ & LL & LL & Avg & Avg & Avg \\
\hline & low & VL & $\mathrm{L}$ & $\mathrm{L}$ & LL & LL & Avg & Avg & Avg & LH \\
\hline & little low & $\mathrm{L}$ & $\mathrm{L}$ & LL & LL & Avg & Avg & Avg & LH & $\mathrm{LH}$ \\
\hline & average & $\mathrm{L}$ & LL & LL & Avg & Avg & Avg & $\mathrm{LH}$ & LH & $\mathrm{H}$ \\
\hline & little high & LL & LL & Avg & Avg & Avg & $\mathrm{LH}$ & LH & $\mathrm{H}$ & $\mathrm{H}$ \\
\hline & high & LL & Avg & Avg & Avg & $\mathrm{LH}$ & LH & $\mathrm{H}$ & $\mathrm{H}$ & $\mathrm{VH}$ \\
\hline & very high & Avg & Avg & Avg & $\mathrm{LH}$ & LH & $\mathrm{H}$ & $\mathrm{H}$ & $\mathrm{VH}$ & VH \\
\hline & absolute & Avg & Avg & $\mathrm{LH}$ & LH & $\mathrm{H}$ & $\mathrm{H}$ & $\mathrm{VH}$ & $\mathrm{VH}$ & Abs \\
\hline
\end{tabular}

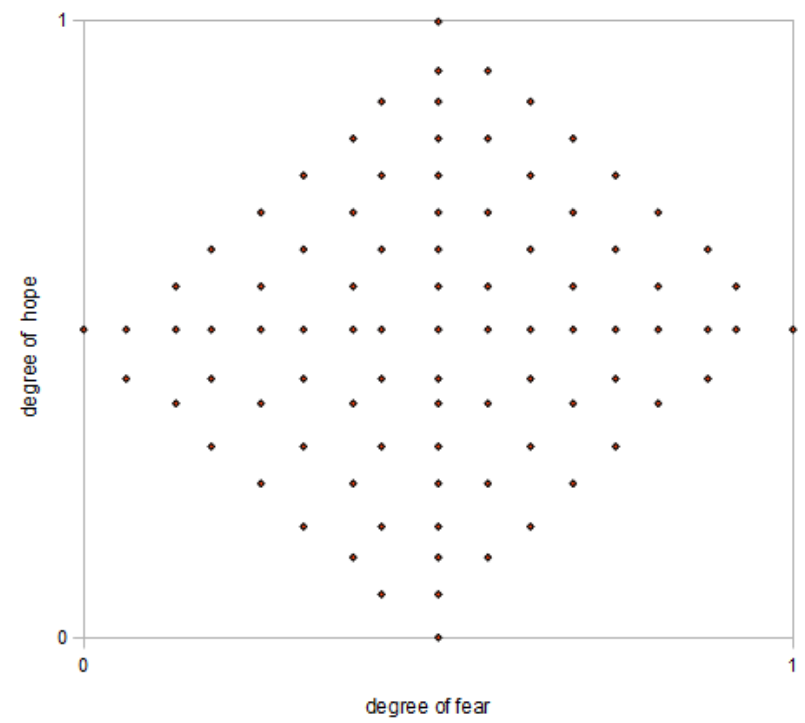

Figure 2. Relationship between degree of hope and fear about the same event

The first two factors form the fact that $i$ hoped for $\varphi$, so Satisfaction could be represented via Hope as follows:

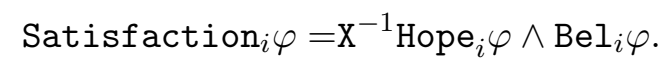

As the factor of $\operatorname{Bel}_{i} \varphi$ has only two statuses, the degree of satisfaction thus depends on the degree of hope: the more $\varphi$ was hoped for $i$, the more $i$ is satisfied when $\varphi$ is realized, and vise versa. And 
regarding the degree of hope, the degree of satisfaction is estimated as:

$$
\begin{aligned}
d\left(\operatorname{Satisfaction}_{i} \varphi\right) & =f_{\text {spa }}\left(d\left(\operatorname{Hope}_{i} \varphi\right), d\left(\operatorname{Bel}_{i} \varphi\right)\right) \\
& =f_{\text {spa }}\left(f_{d p a}\left(d\left(\operatorname{Goal}_{i} \varphi\right), d\left(\operatorname{Poss}_{i} \mathrm{~F} \varphi\right)\right), d\left(\operatorname{Bel}_{i} \varphi\right)\right)
\end{aligned}
$$

where $f_{s p a}$ is a $S P A$, and $f_{d p a}$ is a $D P A$. For instance, when using $f_{s p a}(x, y)=x * y$, the degree of satisfaction is related to that of hope indicated in Table 4.

Table 4. Variations of satisfaction's degree based on its contribution factors

\begin{tabular}{|c|c|c|}
\hline Hope $_{i} \varphi$ & Bel $_{i} \varphi$ & Satisfaction $_{i} \varphi$ \\
\hline not at all & yes & not at all \\
very low & yes & very low \\
low & yes & low \\
little low & yes & little low \\
average & yes & average \\
little high & yes & little high \\
high & yes & high \\
very high & yes & very high \\
absolute & yes & absolute \\
\hline
\end{tabular}

The same analysis in the case of Disappointment, it is defined by three factors [26]: (i) Agent $i$ undesired a proposition $\varphi$; (ii) agent $i$ used to believe that $\neg \varphi$ might be true in the near future; and (iii) agent $i$ now experiences that $\varphi$ is really the case. The concept of Disappointment is accordingly represented as follows:

$$
\begin{aligned}
\text { Disappointment }_{i} \varphi & =\mathrm{X}^{-1}\left(\mathrm{Goal}_{i} \neg \varphi \wedge \operatorname{Poss}_{i} \mathrm{~F} \neg \varphi\right) \wedge \operatorname{Bel}_{i} \varphi \\
& =\mathrm{X}^{-1} \mathrm{Hope}_{i} \neg \varphi \wedge \operatorname{Bel}_{i} \varphi
\end{aligned}
$$

And the degree of disappointment as:

$$
\begin{aligned}
d\left(\text { Disappointment }_{i} \varphi\right) & =f_{\text {spa }}\left(d\left(\operatorname{Hope}_{i} \neg \varphi\right), d\left(\operatorname{Bel}_{i} \varphi\right)\right) \\
& =f_{\text {spa }}\left(f_{\text {dpa }}\left(d\left(\operatorname{Goal}_{i} \neg \varphi\right), d\left(\operatorname{Poss}_{i} \mathrm{~F} \varphi\right)\right), d\left(\operatorname{Bel}_{i} \varphi\right)\right)
\end{aligned}
$$

where $f_{s p a}$ is a $S P A$, and $f_{d p a}$ is a $D P A$. For instance, when using $f_{\text {spa }}(x, y)=x * y$, the degree of disappointment is related to that of hope (of not occur) indicated in Table 5.

\subsection{Fear-confirmed/Relief}

Fear-confirmed is defined by three factors [26]: (i) A proposition $\varphi$ was undesirable for agent $i$; (ii) agent $i$ believed that $\varphi$ might be true in the near future; and (iii) agent $i$ now experiences that $\varphi$ is really true. The concept of Fear-confirmed is accordingly represented as:

$$
\text { FearConfirmed }_{i} \varphi=\mathrm{X}^{-1}\left(\operatorname{Goal}_{i} \neg \varphi \wedge \operatorname{Poss}_{i} \mathrm{~F} \varphi\right) \wedge \operatorname{Bel}_{i} \varphi .
$$

The first two factors form the fact that $i$ ware scared for $\neg \varphi$, so Fear-confirmed could be represented via Fear as follows:

$$
\text { FearConfirmed }_{i} \varphi=\mathrm{X}^{-1} \operatorname{Fear}_{i} \varphi \wedge \operatorname{Bel}_{i} \varphi
$$


Table 5. Variations of disappointment's degree based on its contribution factors

\begin{tabular}{|c|c|c|}
\hline Hope $_{i} \neg \varphi$ & $\operatorname{Bel}_{i} \varphi$ & Disappointment $_{i} \varphi$ \\
\hline not at all & yes & not at all \\
very low & yes & very low \\
low & yes & low \\
little low & yes & little low \\
average & yes & average \\
little high & yes & little high \\
high & yes & high \\
very high & yes & very high \\
absolute & yes & absolute \\
\hline
\end{tabular}

Table 6. Variations of fear-confirmed's degree based on its contribution factors

\begin{tabular}{|c|c|c|}
\hline Fear $_{i} \varphi$ & $\operatorname{Bel}_{i} \varphi$ & FearConfirmed $_{i}$ \\
\hline not at all & yes & not at all \\
very low & yes & very low \\
low & yes & low \\
little low & yes & little low \\
average & yes & average \\
little high & yes & little high \\
high & yes & high \\
very high & yes & very high \\
absolute & yes & absolute \\
\hline
\end{tabular}

As the factor of $\operatorname{Bel}_{i} \varphi$ has only two statuses, the degree of fear-confirmed thus depends on the degree of fear: the more $\varphi$ was scared for $i$, the more $i$ is fear-confirmed when $\varphi$ is realized, and vise versa. And regarding the degree of fear, the degree of fear-confirmed is estimated as:

$$
\begin{aligned}
d\left(\text { FearConfirmed }_{i} \varphi\right) & =f_{\text {spa }}\left(d\left(\operatorname{Fear}_{i} \varphi\right), d\left(\operatorname{Bel}_{i} \varphi\right)\right) \\
& =f_{\text {spa }}\left(f_{d p a}\left(d\left(\operatorname{Goal}_{i} \neg \varphi\right), d\left(\operatorname{Poss}_{i} \mathrm{~F} \varphi\right)\right), d\left(\operatorname{Bel}_{i} \varphi\right)\right)
\end{aligned}
$$

where $f_{s p a}$ is a $S P A$, and $f_{d p a}$ is a $D P A$. For instance, when using $f_{s p a}(x, y)=x * y$, the degree of fear-confirmed is related to that of fear indicated in Table 6 .

The same analysis for Relief, it is defined by three factors [26]: (i) A proposition $\varphi$ was desirable for agent $i$; (ii) agent $i$ believed that $\neg \varphi$ might be true in the near future; and (iii) agent $i$ now experiences that $\varphi$ is really true. The concept of Relief is accordingly represented as:

$$
\begin{aligned}
\operatorname{Relief} \varphi & =\mathrm{X}^{-1}\left(\operatorname{Goal}_{i} \varphi \wedge \operatorname{Poss}_{i} \mathrm{~F} \neg \varphi\right) \wedge \operatorname{Bel}_{i} \varphi \\
& =\mathrm{X}^{-1} \operatorname{Fear}_{i} \neg \varphi \wedge \operatorname{Bel}_{i} \varphi .
\end{aligned}
$$

And the degree of relief as:

$$
\begin{aligned}
d(\operatorname{Relief} \varphi) & =f_{\text {spa }}\left(d\left(\operatorname{Fear}_{i} \neg \varphi\right), d\left(\operatorname{Bel}_{i} \varphi\right)\right) \\
& =f_{\text {spa }}\left(f_{\text {dpa }}\left(d\left(\operatorname{Goal}_{i} \varphi\right), d\left(\operatorname{Poss}_{i} \mathrm{~F} \neg \varphi\right)\right), d\left(\operatorname{Bel}_{i} \varphi\right)\right)
\end{aligned}
$$


where $f_{s p a}$ is a $S P A$, and $f_{d p a}$ is a $D P A$. For instance, when using $f_{s p a}(x, y)=x * y$, the degree of relief is related to that of fear (of not occur) indicated in Table 7.

Table 7. Variations of relief's degree based on its contribution factors

\begin{tabular}{|c|c|c|}
\hline Fear $_{i} \neg \varphi$ & $\operatorname{Bel}_{i} \varphi$ & $\operatorname{Relief} \varphi$ \\
\hline not at all & yes & not at all \\
very low & yes & very low \\
low & yes & low \\
little low & yes & little low \\
average & yes & average \\
little high & yes & little high \\
high & yes & high \\
very high & yes & very high \\
absolute & yes & absolute \\
\hline
\end{tabular}

\section{RELATED WORKS}

This section compares and discusses about the some related works in the recent literature. Particularly, the works of Adam et al. [1], Bonnefon et al. [3, 4] and Nguyen [21], Meyer [20], Ochs et al. $[24,25]$, and Steunebrink et al. [36, 38].

The model of Adam et al. [1] is also based on the same foundation model of emotion as the proposed model, the theory of Ortony et al. [26]. At the logical level, their formal framework is based on the modal logic of belief, choice, time, and action of Herzig and Longin [14] which is a refinement of Cohen and Levesque's works [9] and the BDI modal logic of Georgeff et al. [12]. The difference is on the semantic of time: in their logic, a story is a set of possible worlds plus some properties of the corresponding accessibility relation that entails the linearity of time. While in the proposed logic, a story is a primitive of the semantics. At the quantitative level, their model does not support to estimate the degree of emotion.

The model of Bonnefon et al. [3, 4] and Nguyen [21] also based on the theory of Ortony et al. [26]. Their logic is also based on the modal logic of belief, choice, time, and action of Herzig and Longin [14] which is a refinement of Cohen and Levesque's works [9] and the BDI modal logic of Georgeff et al. [12]. The difference is that their model considered only the qualitative aspect of emotion, but not quantitative aspect: their model can not estimate the degree of emotion, except two bipolar values: true or false. On the line with these works, the model in this paper bas been enriched with the ability to estimate the degree of emotion by adding a hedge algebra and its extension with fuzzy logic to model the quantitative aspect of emotion.

Meyer [20] presents a logic which enables to reason about the dynamics of emotional states of agent. This logic is based on a BDI model [12], and the framework of dynamic logic and (an extension of) the KARO framework [39]. Therefore, they focus on the action in their emotion's definition (original of dynamic logic). This is the main difference from us, but the principle is compatible. Their model does not support to estimate the degree of emotion.

Ochs et al. [24, 25] also use the theory of Ortony et al. [26] as a foundation model. They also based a logic of Belief and Desire to construct their emotional model. The main difference from the proposed model in this paper is that they based on the capability of emotion's owner. Their model 
does not support to estimate the degree of emotion.

Steunebrink et al. $[36,38]$ also use the theory of Ortony et al. [26] as a foundation model but they formalize all twenty-two emotions of Ortony et al. as primitive operators in order to reason emotion effects on action. Their model is thus far from the proposed model in this paper: each emotion is presented as a primitive etiquette and therefore, there is no common component among emotions. Their model does not support to estimate the degree of emotion.

\section{DISCUSSION}

This section discusses about the ability of applying emotion models as well as the proposed model into some daily real life application, and some limits of the proposed model.

\subsection{Applications of emotion models}

As mentioned in the introduction section, there are three main reasons why emotions become an active research area in computer science. This section presents some scenarios in which, the emotion (and possibly the model) could be taken into account as one of the mains aspects of a daily real life application.

\subsubsection{Scenario 1: At a smart home}

Pierre is a French living in a smart home in Paris. His favorite team of rugby is evidently France, and his home also knows it. Today, there is the final match of The Rugby World Championship between France and New Zealand. The match ends during the return of Pierre after a working day at his office, and the winner is France. Pierre and his home are both conscious of this result. Pierre is very happy until home. At the entrance door, the camera observes Pierre face and his home detects that he is very happy. It argues that his happy could be from the event that France wins the final match. Therefore, instead of saying a predictable and boring welcome phrase as "Welcome home Pierre!", via the speakers at the entrance, the smart home could say something more friendly as "Congratulations for your team, Pierre! Viva La France!".

In this scenario, there are some applications of emotion processing:

- The application of recognise the emotion from human face. This helps the smart home to detect the happy of Pierre.

- The application of recognise and reasoning the emotion from it cognitive factor. This enables the smart home to argue that the happy of Pierre could be from the event that France wins the final match. This then leads the behaviour of the smart home more friendly and more appropriated to the real emotional situation of the interaction.

\subsubsection{Scenario 2: In a smart office}

Today is the first day Ann goes to her smart office in New York after returning from a holiday vacation in Maldive. There are three news waiting for her at the office. First, she will be promoted to a higher position. Second, a partner rejected her proposal that she has bided before vacation. And third, a client has already paid for the invoice that she has sent before vacation. The smart office plays the role to tell Ann all news arrived during her vacation: these three news. It knows that the first news could make Ann happy with a higher degree than the third one, and that the second news could 
brings her to a bad emotion. Therefore, the order of news that the smart office tells her is the first news, the third news and then, the second one. This could reduce the degree of the bad emotion when Ann receives the second news.

In this scenario, there are some applications of emotion processing:

- The application of recognise and reasoning the emotion from it cognitive factor. This enables the smart office to estimate the degree of positive emotions to compare what is better for the boss of the office.

- The application of reasoning about the effects of emotions on mood and behaviour, based on a theory that: if there are two news: a good and a bad news. If we know the bad news after the good one, the degree of the bad emotion could be lower than that comes when the bad news is known before the good one. This helps the smart office to choose the good event, which brings some positive emotions, to tell the boss of the office before telling the bad news.

- The application of estimating the degree of emotions. This helps the smart office to estimate the degree of each emotion corresponding to some events, and then to detect which event could bring the highest degree of positive emotion to tell before those could bring a lower degree of positive emotion, and vice versa for the negative emotion. This leads the behaviour of the smart office more efficient in order to increase the effects of positive emotions and to reduce the effects of negative emotion in the real emotional situation of the interaction.

\subsection{Limits of the model}

The proposed model in this paper evidently has still some limits. First, that is problem of verification/validation. In fact, the verification/validation of a logical framework is not an easy mission. Many related logical frameworks (Adam et al. [1], Bonnefon et al. [3, 4] and Nguyen [21]) are not validated yet, but they are popularly accepted, used and cited in the several fields of AI, psychology, neurobiology... This is a limit of the model, and it is considered as a potential future work.

Second, this paper models only eight emotions which have a simple cognitive structure (reaction for an event). many other emotions such as those in groups of composed emotion (c.f. Ortony et al. [26]) are not still modelled. Their cognitive structure is more complex. So some other logic is needed to cover these complex emotions. This could be one of perspective works in the near future.

\section{CONCLUSION}

This paper firstly introduces a logical framework for the representation of emotion based on a logic of belief and a logic of time. Secondly, it introduces a hedge algebra and its extension with fuzzy logic to represent the degree of emotions and that of their cognitive factors. These two aspects of emotion are then combined to estimate the degree of emotions based on the degree of their cognitive factors. The paper estimates nine different degrees (not at all, very low, low, little low, average, little high, high, very high, absolute) of eight emotions (joy, distress, hope, fear, satisfaction, disappointment, fear-confirmed, relief) based on the degree of their cognitive factors.

Although this logic is enough to formalize and estimate the degree of these eight emotions, it is not enough to represent and estimate the degree of other complex emotion such as compound emotions. These current limitations are also the potential perspective for future research. 


\section{REFERENCES}

[1] C. Adam, A. Herzig, and D. Longin, "A logical formalization of the OCC theory of emotions," Synthese, vol. 168, no. 2, pp. 201-248, 2009.

[2] M. Arnold, Emotion and Personality. New York: Columbia University Press, 1960.

[3] J.-F. Bonnefon, D. Longin, and M. H. Nguyen, "Relation of trust and social emotions: A logical approach," in Web Intelligence and Intelligent Agent Technologies, 2009. WI-IAT'09. IEEE/WIC/ACM International Joint Conferences on, vol. 2. IET, 2009, pp. 289-292.

[4] — , "A logical framework for trust-related emotions," Electronic Communications of the EASST, vol. 22, pp. 1-15, 2010.

[5] W. Cannon, Bodily Changes in Pain, Hunger, Fear and Rage, 2nd ed. New York: Appleton, 1929.

[6] N. Cat Ho and W. Wechler, "Hedge algebras: An algebraic approach to structure of sets of linguistic truth values," Fuzzy Sets Systems, vol. 35, no. 3, pp. 281-293, May 1990.

[7] B. F. Chellas, Modal Logic: an Introduction, 1980.

[8] E. M. Clarke, E. A. Emerson, and A. P. Sistla, "Automatic verification of finite-state concurrent systems using temporal logic specifications," ACM Transactions on Programming Languages and Systems, vol. 8, no. 2, pp. 244-263, 1986.

[9] P. R. Cohen and H. J. Levesque, "Intention is choice with commitment," Artificial Intelligence, vol. 42, pp. 213-261, 1990.

[10] M. Fischer and R. Ladner, "Propositional dynamic logic of regular programs," Journal of Computer and System Sciences, vol. 18, no. 2, pp. 194-211, 1979.

[11] N. H. Frijda, The Emotions: Studies in Emotion 85 Social Interaction, ser. Edition de la Maison des Sciences de l'Homme. Paris: Cambridge University Press, 1986.

[12] M. Georgeff, B. Pell, M. Pollack, M. Tambe, and MichaelWooldridge, "The belief-desire-intention model of agency," In J.P. Muller et al. (Eds.): ATAL'98, LNAI 1555, pp. 1-10, 1999.

[13] D. Harel, D. Kozen, and J. Tiuryn, Dynamic Logic. MIT Press, 2000.

[14] A. Herzig and D. Longin, "C\&L intention revisited," in Proceedings of Int. Conf. of knowledge representation and reasoning KR'04. Morgan Kaufmann, 2004, pp. 527-535.

[15] N. C. Ho and H. V. Nam, "An algebraic approach to linguistic hedges in zadehś fuzzy logic," Fuzzy Sets Systems, vol. 129, no. 2, pp. 229-254, Jul. 2002.

[16] N. C. Ho and N. V. Long, "Fuzziness measure on complete hedge algebras and quantifying semantics of terms in linear hedge algebras," Fuzzy Sets Syst., vol. 158, no. 4, pp. 452-471, Feb. 2007.

[17] N. C. Ho and W. Wechler, "Extended hedge algebras and their application to fuzzy logic," Fuzzy Sets Systems, vol. 52, no. 3, pp. 259-281, Dec. 1992. 
[18] W. James, "What is an emotion?" Mind, vol. 9, pp. 188-205, 1884.

[19] R. S. Lazarus, Emotion \& Adaptation. Oxford University Press, 1991.

[20] J.-J. C. Meyer, "Reasoning about emotional agents: Research articles," International Journal of Intelligent Systems, vol. 21, no. 6, pp. 601-619, 2006.

[21] M. H. Nguyen, "A logical framework for trust-related emotions: formal and behavioral results," Ph.D. dissertation, University of Toulouse III, 2010.

[22] — - "Combination of formal logic and hedge algebra to estimate the degree of trust," Journal of Computer Science and Cybernetics, vol. 31, no. 3, pp. 203-213, 2015.

[23] J. Oakley, Morality and the Emotions. London: Routledge and Kegan Paul, 1992.

[24] M. Ochs, K. Devooght, D. Sadek, and C. Pelachaud, "A computational model of capabilitybased emotion elicitation for rational agent," in Proceedings of the 1st workshop on Emotion and Computing - Current Research and Future Impact, D. Reichardt, P. Levi, and J.-J. C. Meyer, Eds., Bremen, Germany, June 2006.

[25] M. Ochs, R. Niewiadomski, C. Pelachaud, and D. Sadek, "Intelligent expressions of emotions," in First International Conference, ACII 2005, Beijing, China, October 22-24, 2005, vol. 3784/2005. Springer Berlin / Heidelberg, 2005, pp. 707-714.

[26] A. Ortony, G. L. Clore, and A. Collins, The Congnitive Structure of Emotions. The Cambridge University Press, 1988.

[27] H. V. D. Parunak, R. Bisson, R. M. Sven Brueckner, and J. Sauter, "A model of emotions for situated agents," AAMAS'06, pp. 993-995, May 2006.

[28] R. W. Picard, Affective computing. MIT Press, 1997.

[29] A. N. Prior, Time and Modality. Oxford: Clarendon Press, 1957.

[30] R. Reisenzein, "Emotions as metarepresentational states of mind: Naturalizing the belief-desire theory of emotion," Cognitive Systems Research, vol. 10, no. 1, pp. 6-20, 2009.

[31] I. Roseman and C. Smith, "Appraisal theories: Overview, assumptions, varieties, controversies," in Appraisal processes in emotion: Theory, Methods, Research, A. S. K. R. Scherer and T. Johnstone, Eds. Oxford University Press, 2001, pp. 3-19.

[32] S. Schacter and J. Singer, "Cognitive, social and physiological determinants of emotional states," Psychological Review, vol. 69, pp. 379-399, 1962.

[33] K. R. Scherer, Appraisal Processes in Emotion : Theory, Methods, Research. New York: Oxford University Press, 2001, ch. Appraisal Considered as a Process of Multilevel Sequential Checking, pp. 92-120.

[34] Stanford, Emotion, Stanford Encyclopedia of Philosophy, http://plato.stanford.edu/entries/emotion/, 2008. 
[35] L. Stephane, "Cognitive and emotional human models within a multi-agent framework," in Proceedings of the International Conference of Human - Computer Interface, Beijing, China, 2007.

[36] B. R. Steunebrink, M. Dastani, and J.-J. C. Meyer, "A logic of emotions for intelligent agents," in Proceedings of the Twenty-Second AAAI Conference on Artificial Intelligence, July 22-26, 2007, Vancouver, British Columbia, Canada. AAAI Press, 2007, pp. 142-147.

[37] — , "Towards a quantitative model of emotions for intelligent agents," in Proceedings of the 2nd Workshop on Emotion and Computing - Current Research and Future Impact, D. Reichardt and P. Levi, Eds., Osnabrck, Germany, 2007.

[38] — , "A formal model of emotion-based action tendency for intelligent agents," in Progress in Artificial Intelligence, 14th Portuguese Conference on Artificial Intelligence, EPIA 2009, Aveiro, Portugal, October 12-15, 2009, ser. Lecture Notes in Computer Science, L. S. Lopes, N. Lau, P. Mariano, and L. M. Rocha, Eds., vol. 5816. Springer, 2009, pp. 174-186.

[39] W. van der Hoek, B. van Linder, and J.-J. C. Meyer, "An integrated modal approach to rational agents," in Foundations of Rational Agency, M. Wooldridge and A. Rao, Eds. Kluwer, Dordrecht: Applied Logic Series 14, 1998, pp. 133-168. 